\title{
La competencia deportiva en pueblos amerindios: casos heterodoxos para entender otras lógicas de actuación Sports competition in Amerindian villages: heterodox cases to understand other actuation logic Ángel Acuña Delgado \\ Universidad de Granada (España)
}

\begin{abstract}
Resumen. El propósito general de este trabajo es ofrecer hechos significativos que permitan entender otras formas de interpretar la competencia en la actividad deportiva. En tal sentido se presentan aquí dos casos concretos de deportes de competición en pueblos amerindios, uno arraigado en la tradición: la carrera rarámuri, y otro importado del exterior: el fútbol yanomami. A partir de los datos producidos como fruto de la metodología etnográfica empleada en ambos pueblos (20012005 con rarámuris; 2004-2007 con yanomamis), se responde a seis objetivos básicos: describir las peculiaridades de ambas manifestaciones deportivas; resaltar el papel que juega el contexto en la interpretación y reinterpretación de la competencia; analizar las implicaciones y consecuencias que se derivan de ella; observar cuál es el espíritu e intencionalidad de las normas aplicadas; destacar patrones comunes y reflexionar sobre los valores que se desprenden en ambos casos. Los resultados ofrecen un claro contraste con lo que en materia de competencia deportiva es habitual en las sociedades modernas, y constituyen un testimonio de lo que otros pueblos apartados de los medios de comunicación pueden aportar.
\end{abstract}

Palabras claves. deporte de competición, indígena, carrera, fútbol, valores.

\begin{abstract}
The general purpose of this work is to offer significant facts that allow understand other ways of interpreting competition in sports activity. In this sense, two specific cases of competition sports in Amerindian villages are presented here, one born from the tradition: the Rarámuri race, and another imported from abroad: Yanomami football. From the data produced, as a result of the ethnographic methodology used in both towns (2001-2005 with Rarámuris; 2004-2007 with Yanomamis), six basic objectives are threatened: to describe the peculiarities of both sporting events; highlight the role of context in the interpretation and reinterpretation of competition; analyze the implications and consequences of competition; observe the spirit and intentionality of the rules applied; highlight common patterns and reflect on the values that emerge in both cases. The results stand in stark contrast to what is common in sport competition in modern societies, and are a testament to what other peoples separated from the media can bring.
\end{abstract}

Key Words. competition sport, indigenous, foot race, football, values.

\section{Introducción}

Como producto cultural, el concepto de deporte y su práctica ha cambiado mucho desde el siglo XII que estuviera asociado esencialmente a la idea de transportarse, evadirse, divertirse (Piernavieja, 1966), hasta el siglo XX y principios del XXI, que en su diversidad constituye uno de los fenómenos culturales más extendidos por el planeta, capaz de adoptar infinidad de formas, desempeñar numerosas funciones y activar profundas emociones. En época contemporánea son bastantes los autores que lo han clasificado de forma dicotómica: deporte práctica - deporte espectáculo (Cagigal, 1981b), deporte activo - deporte pasivo (Cazorla, 1979), deporte formal - deporte informal (García Ferrando,

Fecha recepción: 28-04-21. Fecha de aceptación: 12-07-21 Angel Acuña Delgado

acuna@ugr.es
1990), deporte profesional - deporte amateur, deporte individual - deporte colectivo, etc. Otros han ordenado su espectro en un mayor número de categorías (Blanchard \& Chesca, 1986; Parlebas, 2001). Especialmente sugerente resulta la visión ofrecida por Heineman (1991) al considerar el deporte moderno como sistema que obedece a un doble lineamiento: 1. como sistema cerrado se incluirían todas aquellas actividades motrices, competitivas, regladas e institucionalizadas como deporte; y 2. como sistema abierto aquellas otras que están marcadas bien por su dimensión lúdica o higiénicosanitaria, y contribuyen de algún modo a la realización personal. Conceptos que se aproximan mucho a la distinción existente entre deporte de competición y deporte de recreo. Aplicado al contexto español Pérez Flores (2015) ofrece más recientemente una tipología de deportistas y de modelos deportivos contemporáneos.

Más allá de los motivos que ligan su práctica con el 
mantenimiento o mejora de la forma física, la salud, la diversión, la sensación de riesgo, la autosuperación, la rivalidad, u otras maneras de realización personal o profesional, su gestión posee poderosas implicaciones y consecuencias con la actividad económica, social, política e ideológica de las personas y los pueblos, convirtiéndose en muchos casos en signo de distinción (Bourdieu, 1988). El deporte despierta, por tanto, intereses de todo tipo y atrae la atención de muchos, ya sea como práctica o como espectáculo (Cagigal, 1981a). No obstante, de entre todas sus posibilidades hay un rasgo que destaca y que en sí mismo ha generado toda una tipología dentro del campo: la competición. El deporte de competición, ya sea en modalidad individual o colectiva, satisface las aspiraciones de quienes desean alcanzar determinadas metas o ciertos niveles de exigencia, mediante la superación de rivales que buscan lo mismo. Los deportes que tratamos en este trabajo se enmarcan dentro de esa categoría, en la que la actividad cobra interés y sentido a través de la competencia física.

Caillois (1958) ya hacía referencia al espíritu agonístico (agon) o de competición existente en el deporte, espíritu que generaba estrategias de juego en la Edad Media para luego transferirlas al campo de batalla. Eso ocurría cuando la guerra se hacía en combate cuerpo a cuerpo, sin armas de fuego, y se decidía por la bravura, habilidad y capacidad estratégica de los contendientes, estableciendo así una analogía entre el deporte y la guerra, al servir el primero como preparación para la segunda. El estudio de Sipes (1973) por su parte, al correlacionar los deportes de combate con la belicosidad guerrera, establecía dos modelos interpretativos: el instintivista, según el cual en las distintas sociedades se da una relación inversa entre la disposición a la guerra y los deportes de combate; y el de aprendizaje cultural, en el que la relación sería directa. De uno u otro modo, en sus conclusiones establecía que la agresividad es posible canalizar y el deporte se presenta como una actividad capaz de modelarla, bien de manera espontánea y natural (instintiva) o bien de manera deliberadamente orientada (por aprendizaje). Hay que añadir, no obstante, que la competencia en los deportes que la admiten forma parte de su lógica y no tiene por qué desencadenar conflicto; y en relación con la agresividad, frente a las teorías que consideran que la favorece (Lueschen, 1970), están las otras que consideran que la libera (Stone, 1971). Teorías en las que cabe hacer también la distinción entre practicantes y espectadores para observar uno u otro tipo de relación (Lüschen \& Weis, 1976).
En la sociedad de consumo que estamos instalados, basada en el libre mercado, en la libre competencia, cabe pensar que el deporte de competición tiene buen encaje como herramienta para aprender a ganar y a perder, a asumir las victorias y las derrotas para transferir la enseñanza del ámbito deportivo al extradeportivo. Sabemos que el deporte está cargado de valores y que éstos pueden ser extrapolables fuera de él a otros órdenes de la vida. Así lo percibió Nelson Mandela, al manifestar: «Vamos a usar el deporte para la construcción nacional y para promover todas las ideas que creemos que conducirán a la paz y la estabilidad en nuestro país» (Carlin, 2009, p. 209), con motivo del Campeonato Mundial de Rugby de 1995, celebrado en Sudáfrica. Aunque, sabemos también, haciéndonos eco del pensamiento de Huxley, citado por Arnold en Santiago (2002, p. 1), que: «[...] como cualquier instrumento inventado por el hombre, el deporte puede utilizarse con buenos y malos propósitos.» $\mathrm{O}$, más aún, que aunque el propósito sea bienintencionado, no siempre se cumplen las expectativas. El deporte de competición se ha venido usando en las últimas décadas como medio para la educación en valores (Bredemeier, 1994; Gutiérrez, 1995; Ossorio, 2002; Pérez Turpin, 2002; Durán \& Jiménez Martín, 2006; Sánchez Pato, Mosquera, Bada \& Cebrián, 2008; Durán, 2013; Fernández-Río, Cecchini \& Méndez-Giménez, 2014; Veroz, Yagüe \& Tabernero, 2015; Monjas, Ponce \& Gea, 2015), propiciándose campañas con estrellas deportivas como modelos del buen hacer y del saber estar, bajo el principio que «unas veces se gana y otras se aprende», y tratan de inculcar en los jóvenes que lo más importante es participar, compartir y divertirse. Campañas y programas, no obstante, que no han obtenido los resultados deseados en todos los casos, al existir como contrapunto un extendido mensaje transmitido de palabra y obra por otros destacados deportistas y clubes, que manifiestan no soportar la derrota y colocan la victoria por encima de todo, cueste lo que cueste.

La casuística, sin embargo, es muy amplia, los deportes modernos de competición llegan a casi todos los lugares a través de las ondas y son conocidos y practicados, incluso por grupos humanos que viven en territorios de difícil acceso, alejados de los espacios urbanos. Asimismo siguen existiendo aún tradiciones deportivas de competencia que forman parte importante del acervo cultural de los pueblos. En esta línea, el presente trabajo centra la atención en dos casos concretos como prototipos de las dos situaciones mencionadas; dos casos de comunidades amerindias que no han recibido ningu- 
na campaña de educación en valores a través del deporte, las cuales nos permitirán observar qué valores le atribuyen o se desprenden de manera espontánea de sus respectivas prácticas en sus correspondientes contextos. El primer caso trata de la carrera de bola y ariweta rarámuri, costumbre arraigada en la tradición, de la que veremos qué sentidos posee, cómo se afronta la competencia, y qué valores se transfieren a la vida social.Y el segundo caso trata del fútbol yanomami, para analizar cómo este pueblo reinterpreta la práctica de dicho deporte en el plano competitivo, impregnándolo de su propia idiosincrasia. Casos que en definitiva nos permitirán ofrecer nuevas lecturas de la competición en el deporte y reflexionar sobre ellas.

Con las reservas que supone ofrecer imágenes generales, como breve reseña etnográfica que nos acerque al contexto geográfico y socio-cultural en el que se inscriben las poblaciones referidas, a modo de aproximación podemos decir de los Rarámuri que la mayor parte se encuentran ubicados en la sierra Tarahumara, al suroeste del Estado de Chihuahua (México), territorio montañoso que ocupa una extensión de $60.000 \mathrm{~km}^{2}$, y una altitud que va desde los 300 hasta los 3000 m.s.n.m., distinguiéndose dos ecosistemas claramente diferenciados: la Alta y la Baja Tarahumara (sierra y barranca respectivamente). Con una demografía en progresivo ascenso, a finales del siglo XX se estimaba una población de unos 50.000 personas (INEGI, 1995), que en 2015 pasó a concretarse en 73.856 (INEGI, 2015). Aunque parte de la población reside en la ciudad de Chihuahua y en las cabeceras municipales, la mayoría sigue un patrón de asentamiento disperso, formando pequeñas comunidades o rancherías. Su economía de subsistencia se basa en el agropastoreo: el cultivo del maíz y la cría de chivas y vacas, que algunas familias complementan con la producción de artesanía, aunque con escasos beneficios. En lo cotidiano la independencia marca las relaciones interfamiliares, pero existen importantes instituciones que articulan la vida social como son el compadrazgo (relaciones entre familias de ahijados y padrinos de bautizo), las reuniones dominicales para asistir a misa y/o escuchar el nawésari (mensaje del siríame o jefe de comunidad), las convocatorias de carreras tradicionales, la kórima (costumbre solidaria de prestar ayuda a quienes lo necesitan), y especialmente el complejo del tesgüino (bebida fermentada de maíz, presente en el tiempo de fiesta, que genera importantes redes sociales). Pueblo de profundas creencias religiosas, muy influenciado por la iglesia católica, pero con una arraigada cosmovisión de carácter panteísta-animista, que da lugar a numerosas expresiones sincréticas. Para profundizar en todos estos aspectos y obtener una idea del proceso de cambio seguido por los Rarámuri en el último siglo, se recomienda entre otras lecturas, la producida por los siguientes autores: Lumholtz (1994 [1902]; Bennett y Zingg (1978 [1935]); Kennedy (1970); Merrill (1992); Acuña (2006).

Los Yanomami, por su parte, están adaptados a la selva tropical húmeda, ocupando una extensión aproximada de $192.000 \mathrm{~km}^{2}$ entre Venezuela y Brasil. Los del lado venezolano (con quienes se llevó a cabo el trabajo de campo) se asientan en el Estado Amazonas y Bolívar, o más concretamente en el Parque Nacional ParimaTapirapeco y Reserva de la Biosfera Alto OrinocoCasiquiare (Áreas Bajo Régimen de Administración Especial). Según algunas estimaciones, para 2002 su demografía podría haber superado las 27.000 personas, algo más de 15.000 en Venezuela y unas 12.500 en Brasil (Mattei-Muller, 2007, 18). Datos oficiales más recientes, proporcionados por el Instituto Nacional de Estadística, que no dejan de ser también estimativos, arrojan la cifra de 9.569 en el territorio venezolano para 2011 (I.N.E., 2011). La inmensa mayoría viven semiaislados en shaponos (viviendas-poblados comunitarios) de menos de 100 personas, alejados de los lugares de influencia criolla y misionera; muestran muy poca participación en la política regional y mucha solidez cultural. Su economía de subsistencia está basada en la horticultura, caza, pesca y recolección silvestre. Desarrollan una vida social intensa, con reparto de papeles entre hombres y mujeres: los primeros dedicados a tareas de abastecimiento y producción de alimentos, construcción del shapono y fabricación de armas para la caza y la guerra; y las segundas, involucradas también en el abastecimiento, elaboran utensilios, y se responsabilizan de la crianza y la preparación de alimentos. Se trata de una sociedad igualitaria en términos socio-económicos, aunque con una acentuada dominancia masculina. El chamanismo constituye una constante en la vida social, así como su tendencia guerrera. La valentía (ser waitheri, guerrero, bravo) y la generosidad (desprendido de lo material, no mezquino) destacan como principales valores personales. Y su cosmovisión se halla penetrada por el mundo de los hékuras, espíritus progenitores de todo lo que existe (Barandiarán, 1965), imprescindibles en el tratamiento de la enfermedad y en la interpretación de la realidad. Entre las numerosas obras que permiten profundizar en todos estos aspectos, son recomendables las escritas por Barandiarán (1965); Chagnon (1968); Lizot (1976); Alès (1984); Albert (1989); 
Chiappino (2003); Mattei-Muller (2007).

Como pueblo o grupo étnico, tanto Rarámuri como Yanomami poseen obviamente un margen de diversidad interna en su ser cultural. Es por ello que la descripción anterior de carácter general debe matizarse con la existencia de un cierto grado de transformación en el interior de cada grupo, que no los hace a todos iguales ni ajustarse al mismo patrón. Por otro lado el paso del tiempo y con él de las generaciones, constituyen igualmente en mayor o menor medida un importante factor de cambio. Entre los Rarámuri se dispone de un amplio margen de variabilidad: muchas familias y comunidades mantienen escasos contactos con el exterior; otras forman comunidades mixtas con familias mestizas y criollas, con quienes se mezclan también matrimonialmente; y otras se han incorporado a la vida citadina, aunque vivan segregadas en áreas periféricas. Las vías de penetración en la Tarahumara por caminos carreteros facilitan la movilidad para entrar o salir de la sierra cuando se desee, y el acceso a internet ya es posible en los núcleos más poblados. El hecho de contar con un $90.9 \%$ de la población bilingüe (rarámuri-castellano) y un $9.1 \%$ de hablantes exclusivamente rarámuri (INEGI, 2015), es significativo para entender el grado de acercamiento o conexión con la sociedad nacional. Los Yanomami, por su parte, aunque posean igualmente apreciables diferencias al comparar patrones culturales entre unas y otras familias o comunidades, y el cambio esté presente en mayor o menor medida con el paso de las generaciones y los contactos interétnicos, la mayoría de la población se ajusta a modelos más o menos parecidos que reproducen hábitos tradicionales. Lo que no impide que en las comunidades más pobladas, como Ocamo o Mavaca, se pueda ver la televisión por cable, encontrar yanomamis con celulares (teléfonos móviles), e incluso observar a familias bajar por río desde áreas muy alejadas hasta Esmeralda (poblado capital del Municipio Alto Orinoco), para recibir alguna regalía del Estado y tomar coca cola. Sin disponer de cifras fiables sobre el grado de bilingüismo de este pueblo, por la experiencia de campo vivida se estima que no sería superior a un 1 o 2\% de la población total. El hecho lingüístico pone de manifiesto el distanciamiento yanomami del resto de la sociedad nacional, y la mayoritaria opción de vivir alejados de los agentes externos, con quienes tienen escasos contactos.

\section{Objetivos y metodología}

El propósito general de este trabajo es ofrecer he- chos significativos que permitan entender otras formas de interpretar la competencia en la actividad deportiva. Hechos que ocurren en contextos geográficos alejados de la sociedad de consumo, y no por pasar desapercibidos o ser invisibilizados en los medios de comunicación deben dejar de ser considerados como parte de la diversidad de respuestas humanas en un mundo global. En tal sentido, los objetivos perseguidos son los siguientes:

1. Describir las peculiaridades de la tradicional carrera rarámuri y del fútbol practicado por yanomamis.

2. Resaltar el papel que juega el contexto en la interpretación y reinterpretación de dicha competencia.

3. Analizar las implicaciones y consecuencias de la competencia deportiva en ambos casos.

4. Analizar el espíritu de la norma y la intencionalidad latente de la competencia en ambas manifestaciones.

5. Destacar patrones comunes en las respectivas competencias deportivas de rarámuris y yanomamis.

6. Reflexionar sobre los valores que se desprenden del ejercicio de la competencia en ambos casos.

La metodología empleada para el estudio de la carrera rarámuri y del fútbol yanomami, además de otros aspectos de interés, fue estrictamente etnográfica. Entre los rarámuris el trabajo de campo se llevó a cabo en cinco fases sucesivas distribuidas entre 2001 y 2005, acumulando 15 meses de estancia sobre el terreno; las principales comunidades de referencia fueron Norogachi, Choguita, Tehuerichi (Alta Tarahumara), Urique y Cerocahui (Baja Tarahumara), con las rancherías que forman parte de cada una de ellas. Entre los yanomamis el trabajo de campo se desarrolló en cuatro fases desde 2004 a 2007, sumando en total seis meses de convivencia en el lugar, repartidos en los shaponos de Mabetiteri y Mamashatio-teri, así como en el poblado mayor de Ocamo y el Municipio de Esmeralda. En ambos casos fue realizado por un solo investigador ${ }^{1}$. Consciente de la diversidad interna de uno y otro pueblo, los planteamientos expuestos en esta investigación se ciñen a las comunidades estudiadas, sin que se deban extrapolar en términos absolutos a la totalidad de las comunidades que forman el grupo étnico.

El patrón de asentamiento disperso en los rarámuris y agrupado en los yanomamis, motivó que la experiencia etnográfica fuera muy distinta en su dinámica; sin embargo, los medios empleados fueron similares en ambos casos. La principal técnica aplicada para la producción de datos fue la observación participante y no participante, pero siempre sistemática y controlada 
mediante una guía de categorías analíticas, diseñada en consonancia con los objetivos perseguidos. Para el registro de datos se empleó el diario de campo, escrito con ordenador, en él que se fueron introduciendo de manera regular los testimonios escuchados en la cotidianeidad y los hechos significativos que acontecían, descritos con detalle, así como las reflexiones personales del investigador. La entrevista en profundidad y las historias de vida, también ocuparon un papel importante en ambos procesos, con el uso de grabadora magnetofónica. Las personas elegidas respondieron siempre al criterio de amplia experiencia y/o conocimiento sobre determinados temas de interés. Entre los rarámuris se aplicó especialmente a corredores y corredoras, choquéames (organizadores/as de carreras), siríames (jefes de comunidad), owirúames (curanderos), y misioneros. Y entre los yanomamis, con la intervención de un traductor e intérprete, se aplicó a shaporis (chamanes), patas (jefes de poblado), y personas ancianas. De manera complementaria fueron también registradas imágenes fotográficas y en vídeo, tanto de la carrera como del fútbol, que ilustran la dinámica de la acción y el ambiente producido en cada caso. Los datos registrados por cada medio fueron ordenados y analizados por separado de acuerdo a su contenido, para luego realizar un análisis cruzado de los mismos, contrastando observaciones, entrevistas e imágenes; comportamientos y discursos entrelazados dentro de sus respectivos contextos, los cuales fueron interpretados asimismo con el apoyo de fuentes bibliográficas que pudieran arrojar luz a las preguntas desprendidas de los objetivos de investigación.

\section{Resultados: Descripción de ambos eventos deportivos}

\section{La carrera rarámuri}

Históricamente, los rarámuris han sido y son reconocidos por su extraordinaria resistencia en la carrera, capaces de perseguir a pie y capturar caballos salvajes y venados (Lumholtz, 1902), y por su tradicional forma de hacerlo al competir (Diem, 1966). Aunque en la actualidad participen también en ultramaratones convencionales, entre ellos continúan practicándola al modo que acostumbran.

$\mathrm{Su}$ carrera tradicional ${ }^{2}$ posee dos modalidades: rarajípari para hombres, que corren aventando con el pie una bola de madera de unos nueve $\mathrm{cm}$ de diámetro y 240 gm de peso (figura 1); y rowera para la mujer que acompaña su carrera con el lanzamiento de un aro (ariweta) de junquillo de entre ocho y $15 \mathrm{~cm}$. de diá- metro (figura 2) mediante una vara de unos $90 \mathrm{~cm}$ de longitud con la punta curva. En función de la distancia recorrida y las apuestas realizadas se distinguen básicamente dos tipos: las grandes, que en hombres pueden sobrepasar los $200 \mathrm{~km}$ y en mujeres los $100 \mathrm{~km}$, y las pequeñas, de una o varias decenas de kilómetros. Las apuestas varían de acuerdo al grado de expectación que despierten. Aunque se puede correr durante todo el año, la mejor época es primavera y otoño, a fin de evitar las temperaturas extremas de calor y frío. La organización corre a cargo del choquéame, que puede ser hombre o mujer, uno por bando de corredores, que se encarga de divulgar la carrera, organizarla, controlar su desarrollo, casar las apuestas entre quienes participen de ellas, y repartirlas finalmente. La preparación de las o los corredores o corredoras se halla inserta en las actividades propias de la vida cotidiana (agropastoreo, caminatas para visitar a parientes, etc.). Tan solo dos o tres días antes de la gran carrera se procuran algunos cuidados especiales, tales como: tomar caldo de gallina y su carne, recibir la cura espiritual del owirúame, descansar, evitar relaciones sexuales y no tomar alcohol. Las carreras en general y las grandes en particular se organizan para contentar a Onorúame, el Dios Creador que es padre y madre a la vez, la gallina se sacrifica en su nombre, y los corredores han de pasar por el ritual para tener sus almas en $\mathrm{paz}^{3}$.

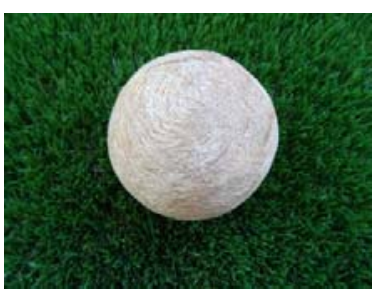
Fuente: Foto del autor
Figura 1. Bola para la carrera de hombres

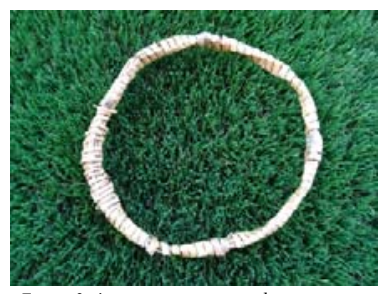

Figura 2, Ariweta para carrera de mujeres Fuente: Foto del autor
Una vez convocado el evento y con los asistentes reunidos en el lugar de encuentro, por lo general, momentos antes de comenzar una carrera grande es ofrecido un nawésari o discurso breve y aleccionador por parte del siríame de la comunidad anfitriona. Las reglas son conocidas: la salida y la llegada se produce en el mismo lugar y ganará el equipo o corredor/a que haga pasar en primer lugar la bola o la ariweta por línea de meta tras completar las vueltas establecidas. El circuito acordado puede ser lineal (de ida y vuelta) o circular, y el relieve y la distancia variable: sobre un circuito de siete $\mathrm{km}$ se pueden dar 30 vueltas, o sobre uno de $30 \mathrm{~km}$ siete vueltas, discurriendo éstas por senderos y caminos de una zona llana de altiplano, o por terreno abrupto de barranca con grandes desniveles. Los dos equipos que com- 
piten han de comenzar con el mismo número de corredores o corredoras, aunque éstos pueden variar desde uno hasta seis como máximo. El rango de edad de quienes intervienen en las grandes carreras es amplio, situándose entre 18 y 50 años, aunque puede haber casos excepcionales que salgan de él. Mientras que el público asistente resulta ser heterogéneo: hombres y mujeres de todas las edades a los que se unen en muchos casos población mestiza. En cuanto al atuendo, los corredores suelen vestir con pantalón corto o zapeta (taparrabos de tela), camiseta, y calzar huaraches (sandalias de suela de caucho con tres agujeros atadas al pie con una tira de cuero); las mujeres lo hacen con su vestido de diario (blusa y falda hasta los tobillos) y sandalias de goma. Es pasado el mediodía, sobre las 14:00 o 15:00 horas, cuando suelen dar comienzo las carreras grandes, y en la línea de salida y meta una persona de confianza se encargará de hacer visible el conteo de vueltas mediante una hilera de piedrecitas, de las que separará las que se han dado de las que quedan por dar.

La técnica de ejecución de la carrera implica también el lanzamiento. En los hombres, a la hora de lanzar la bola un pie le pasa por encima y el otro se apoya justo detrás de ella a fin de impulsarla adelante con fuerza, de manera orientada para que no se salga del camino a seguir. Las mujeres recogen la ariweta del suelo con la vara que llevan en la mano y la lanzan igualmente adelante. Ni la bola, ni la ariweta se puede coger con la mano en ningún momento, ni se puede correr sin ellas, a riesgo de descalificación. En caso de pérdida o rotura se tendría que reemplazar por otra. Como estrategias para desmoralizar y desgastar al contrincante es frecuente colocarse detrás de él sin dejar que se despegue, para luego pasarlo. Dentro del propio equipo de corredores lo normal es turnarse en el lanzamiento de la bola (una por equipo) aquellos con menor fortaleza física, que se irán retirando progresivamente, y reservar así al más preparado o a la más preparada para el final. La dinámica de la carrera, no obstante, es un trabajo de equipo que va más allá de los propios corredores, ya que cada bando está acompañado de un grupo de apoyo para facilitar el avituallamiento ofreciendo agua para beber y pinole (maíz molido y tostado) para comer, vigilar en puntos estratégicos para evitar trampas y alumbrar en la noche con antorchas o linternas, siguiendo por relevos a los corredores. El público asistente anima a los suyos al grito de ¡wériga! ¡wériga! (sigue adelante, no te rajes) y las apuestas, que comenzaron antes de la salida, continúa produciéndose en el transcurso de la carrera, siempre que haya personas interesadas y siem- pre con la presencia del choquéame, que será quien medie para equipararlas y ponerlas de acuerdo. Vestidos y dinero en efectivo son los recursos más empleados en las apuestas, aunque también animales y enseres. En el imaginario colectivo no están ausentes las prácticas mágicas que pueden operar negativamente sobre algunos corredores, sukurúames (hechiceros) que envían a escondidas algún maleficio que merme las fuerzas de unos y los haga perder. Para contrarrestar tales circunstancias y posibles debilitamientos, cada bando cuenta con al menos un owirúame (sanador) que les procure la cura debida.

El final de las carreras grandes se produce con frecuencia por la retirada del rival y no por la conclusión de vueltas. Recorridas, por ejemplo, 28 de las 30 vueltas establecidas, la retirada del que va rezagado por más de un kilómetro sobre el de cabeza, hace que la carrera se pare y tenga ya un ganador, sin necesidad que éste complete las dos vueltas que le faltan por dar. Finalizada la misma, los corredores descansan cuidados por los suyos: son hidratados, alimentados, cubiertos con cobijas, ... y el choquéame del equipo ganador reparte las apuestas. Los ganadores de la misma, de manera voluntaria dejan una pequeña contribución (barata) para el corredor que les ha hecho ganar, así como para el choquéame por su trabajo, a modo de intercambio de dones en compensación por el esfuerzo y dedicación empleada. La apuesta constituye un estímulo muy importante que genera gran expectación y muchas operaciones, antes, durante y después de la carrera; sin embargo, puede convertirse en motivo de conflicto cuando surgen acusaciones de sobornos a corredores, que supuestamente se dejan ganar para beneficiar a quienes apostaron en su contra. A veces tiene lugar una tesgüinada (fiesta con tesgüino) ocasional antes que los asistentes, venidos muchos de muy lejos, regresen a sus casas.Y entre los presentes es habitual concertar allí mismo una nueva fecha, por iniciativa del bando perdedor a modo de revancha, para medir de nuevo las fuerzas.

Además de en la Alta y Baja Tarahumara, la carrera rarámuri se practica de manera regular en la periferia de la ciudad de Chihuahua. Los domingos en la mañana y algún que otro día entre semana, muchas familias rarámuri con residencia permanente o provisional en la ciudad, se dan cita en un lugar próximo al cerro de la Cruz para llevarla a cabo.

\section{El fútbol yanomami}

Aprendido a través del contacto con misioneros católicos y evangélicos, población mestiza y criolla, y tam- 
bién de la televisión, aún con el importante grado de aislamiento que marcan sus vidas, el fútbol hoy día está muy presente entre los yanomamis, tanto en el ámbito comunitario de la vida cotidiana, como en el intercomunitario con la organización de campeonatos. Doble ámbito que veremos a continuación al describir los principales elementos del juego a través de dos casos concretos: el shapono de Mabetiteri y el campeonato de Kukurital.

En la comunidad de Mabetiteri, ubicada en el Alto Ocamo, que en enero de 2006 contaba con 66 personas (31 varones y 35 mujeres), los niños y jóvenes de entre 10 y 16 años aproximadamente juegan al fútbol a diario, en un espacio aproximado de 25 por 18 metros, con pequeñas porterías móviles hechas con piedras o palos clavados, utilizando una parte del patio central del shapono. De manera regular, reducida la actividad laboral en las horas de la tarde, el chamanismo, la conversación, el descanso y jugar al fútbol, cobran una destacada presencia. En Kukurital, por su parte, comunidad rivereña situada en el Alto Orinoco, en el campeonato celebrado durante dos días en enero de 2006, que reunió a cinco equipos o comunidades (Kukurital, Lechosa, Tumba, Chiwire y Ocamo), los partidos se desarrollaron en un campo con dimensiones de 70 por 40 metros, y porterías fijas de madera de cinco por 1.90 metros. Las edades aproximadas de los jugadores oscilaban entre 18 y 35 años.

Si tenemos en cuenta el tiempo que cada cual le dedica a la actividad, podemos apreciar distintos grados de adaptación al juego, no obstante, a grandes trazos podemos diferenciar dos claros niveles: el inicial de quienes están aprendiendo y todos juntos avanzan con el propósito de meter a patadas la pelota en la portería contraria, observado en Mabetiteri; y el de quienes han aprendido el esquema fundamental, repartiéndose en posiciones defensivas y ofensivas, dándole más apertura al juego, llegando a conseguir cierto dominio técnico (regates, fintas) y táctico (desmarques, pases al hueco) para lograr mayor eficacia en la acción, como se observaba en Kukurital. La resistencia, la agilidad, la fuerza, la dureza y la velocidad, destacan como cualidades físicas de los jugadores, en un juego que en su desarrollo, por lo general, resulta ser más físico que técnico y táctico.

El sistema normativo del fútbol yanomami se encuentra abierto a la inclusión o exclusión de pautas reguladoras del juego, tanto en el ámbito comunitario como en los campeonatos intercomunitarios. Las dimensiones del campo y su demarcación están condicionadas por la estructura y el espacio disponible del shapono, existiendo casos en que los campos poseen las dimensiones casi reglamentarias de los campos oficiales. Así como también las porterías tienen dimensiones variables, como apreciamos en los dos casos mencionados. El objeto disputado en el juego es un balón en los campeonatos, pero en las comunidades se juega con lo que se tenga a mano: balones pinchados, pelotas de goma, botes de plástico, envoltorio de hojas a presión atadas con cabuya, o, como también observamos en Mabetiteri, hojas de papel del Nuevo Testamento, arrugadas y atadas con bejuco, hechas una bola de unos $10 \mathrm{~cm}$. de diámetro (figura 3). La duración del partido puede ir desde 15 minutos a más de una hora, con o sin cambio de campo en el juego comunitario; y dos tiempos aproximados de 45 minutos con descanso intermedio y cambio de campo en los campeonatos. En Mabetiteri se jugaba habitualmente descalzo, cubierto con un sencillo calzón corto o calzoncillo; mientras que en Kukurital los equipos se distinguían por su homogénea equipación de camiseta y calzón, y la mayoría calzaban botas de fútbol o zapatillas deportivas. El juego diario se realiza sin árbitro, mientras que en los campeonatos su presencia es indispensable para aplicar las sanciones del reglamento; figura respetada por todos, jugadores y público, por lo que representa, así como sus decisiones, que se suelen acatar sin discusión aun cuando resulten poco coherentes y cometa errores. De manera regular, en el campeonato de Kukurital, al producirse un encontronazo se pitaba siempre falta a favor del jugador que resultaba más dañado, con independencia de quién tuviera la culpa.

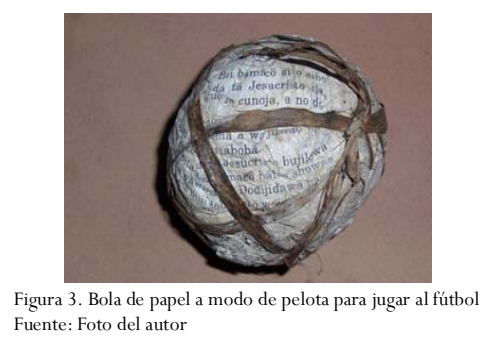

En cuanto al sistema de puntuación o de entender el marcador, en Mabetiteri terminado el partido nadie hablaba de pérdida al afirmar los jugadores de cada equipo haber ganado los goles que habían marcado; de modo, por ejemplo, que un partido que hubiera quedado cinco a tres, se interpretaba que unos habían ganado cinco goles y el otro tres goles, sin que hubiera perdedores. En los campeonatos, el sistema de puntuación se mostraba abierto a las decisiones adoptadas por el Comité de Competición formado con los delegados de los equi- 
pos participantes. En el campeonato de Kukurital en 2006, de los cinco equipos inscritos cada uno jugó dos encuentros por sorteo, contabilizándose como puntos el número de goles marcados por cada equipo y no los partidos ganados; de ese modo, Kukurital resultó ser el primero con siete puntos (por siete goles), seguido de Chiwire con seis puntos (por seis goles), Lechosa con cinco puntos (por cinco goles), y Tumba con tres puntos (por tres goles). Ocamo jugó su primer partido, pero al no haber pagado la cuota de inscripción (45.000 Bs., unos 15 \$) fue descalificado, incidente que provocó la protesta de Chiwire al no contabilizársele los cuatro goles que marcó en ese partido; tal circunstancia motivó que el Comité aceptara la reclamación de Chiwire y acordara que los tres primeros clasificados jugaran finalmente entre sí para decidir el ganador del trofeo: Kukurital jugó primero con Chiwire, y al ser quien metió más goles, jugó seguidamente (sin descanso) con Lechosa, sin que se considerara el sobreesfuerzo que supone jugar dos partidos seguidos de 90 minutos. De todos modos, metió también más goles y acabó ganando el trofeo.

\section{Antropo-lógicas de la competencia depor- tiva en pueblos amerindios}

Llegados a este punto, descritos a grandes rasgos las características de la carrera tradicional rarámuri y del fútbol practicado por los yanomamis, con el foco puesto en la competencia implícita de ambos eventos, responderemos seguidamente a las preguntas centrales de investigación teniendo en cuenta los datos producidos ${ }^{4}$.

¿Qué papel juega el contexto en la interpretación y reinterpretación de la competencia? y ¿qué implicaciones y consecuencias posee en ambos casos?

Como es sabido, todo texto exige de un contexto para ser entendido adecuadamente (Geertz, 1983; Goffman, 1987). El carácter polisémico del comportamiento humano, como texto, necesita del marco de referencia en el que se desenvuelve, para evitar miradas miopes de perspectiva en la búsqueda de sentidos, y en los casos que nos ocupa el contexto ambiental, histórico y socio-cultural desempeña un papel crucial.

En el caso rarámuri, la dispersión territorial de los asentamientos y el modo de subsistencia agropastoril (Bennett \& Zingg, 1978 [1935]), exige de manera permanente largos desplazamientos para los encuentros sociales y conseguir el sustento, lo cual, unido al valor histórico que ha ocupado la resistencia (Basauri, 1926; Velasco, 1987) para hacer frente, primero a los apaches y otros pueblos tribales, luego a los españoles y por último a los mestizos, hace entendible que tal cualidad, entendida en amplios sentidos, se haya convertido en un emblema étnico en el que se identifican bajo el principio de «resistir para vivir», y tengan en la carrera tradicional un motivo para el encuentro y para hablar de ellos mismos. Carrera con la que se distinguen de los no rarámuris, por las peculiaridades que posee, y que también funciona como signo de distinción entre los propios rarámuris, por la rivalidad que encierra entre personas y especialmente entre comunidades o rancherías. Al igual que la resistencia, la competencia constituye un campo de sentido esencial en la carrera.

Por otro lado, la lógica de su economía de subsistencia, al menos de aquellos que viven en el interior de la sierra Tarahumara, exige obtener el máximo aprovechamiento o beneficio de cualquier esfuerzo realizado (Acuña, 2006). En base a tal principio, la competencia física se lleva al terreno económico de la apuesta, ya que hay que correr por algo que favorezca la subsistencia, como es habitual en otras muchas actividades, para que así el gasto energético invertido en la carrera no sea inútil y cobre sentido cultural.

La carrera tradicional, más allá de su consideración como evento deportivo en el plano físico, como ellos mismos lo entienden, posee por tanto importantes connotaciones sociales y económicas. La competencia refuerza las señas de identidad, estrecha los vínculos entre los grupos partidarios de unos u otros corredores o corredoras, los cuales suelen ser representantes de las comunidades o rancherías a las que pertenecen. Pero además contribuye a las transacciones de bienes materiales y su redistribución en las comunidades de la sierra y la barranca que poseen una economía de subsistencia o autoconsumo. Bajo la lógica de doble o nada, la apuesta se presenta como un aliciente esencial de la competencia; la preferencia y apoyo a un bando de corredores se traduce también en arriesgar o invertir algún valor material, implicándose más en ella, y haciéndola así cosa de todos y no solo de quienes corren. Competencia que igualmente discurre en el plano anímico o espiritual con la presencia del owirúame y el sukurúame, del curandero y el hechicero, que en el imaginario colectivo entran en tensión posicionándose a favor o en contra de uno u otro bando, e intervienen de manera decisiva en el resultado final. Llevada así al ámbito de lo numinoso, refuerza las creencias en la permanente lucha entre el bien y el mal, que no está ausente de las carreras, y forma parte importante de su cosmovisión. Competencia generalmente pacífica, pero que en oca- 
siones acarrea controversia y conflicto por distintos motivos: en lo económico, cuando se sospecha que ciertos corredores se han dejado sobornar para su propio beneficio y de quienes inducen el fraude, traicionando la confianza de sus seguidores; en lo deportivo, cuando se denuncia la infracción supuestamente cometida por algún corredor, como puede ser tomar un atajo; o la protesta de un equipo de corredores ante la escasa atención recibida por su grupo de apoyo en los avituallamientos; y en lo espiritual, cuando el resultado adverso para unos es achacado al deficiente papel desempeñado por el owirúame, que no supo dar respuesta a la supuesta acción maléfica de algún sukurúame.

En el caso yanomami, por su parte, hay que tener presente dos aspectos claves: la intensidad de la vida social (Lizot, 1976; Chiappino, 2003) y el ambiente violento en el que se desenvuelven (Chagnon, 1968; Alés, 1984; Albert, 1989). La vida en el shapono de Mabetiteri implica una estrecha relación interfamiliar, la colaboración es estrecha; incluso en algunas actividades económicas, como la pesca en lagunas, se acostumbra el trabajo en grupo para facilitar las capturas. El hekuramou o ritual chamánico, de manera casi invariable se realiza a diario durante horas acaparando la atención de las personas, no solo por su carácter terapéutico sino por ser un motivo de reunión para compartir experiencia y reafirmarse en el mito, en la tradición (Chiappino, 2003). De manera extraordinaria, el reahu o fiesta, generalmente intercomunitaria, cumple también la función de encuentro social, aunque son encuentros que se debaten entre la armonía y el conflicto, entre la colaboración y la competencia, entre declaraciones amistosas y desafíos y actos violentos. En la monotonía de un modo de vida con alto grado de relación social, el fútbol como juego o deporte de competición, es adoptado por los yanomamis de esta comunidad como una forma divertida de entretenimiento, practicada a diario y en paralelo al hekuramou; y es utilizado igualmente como motivo de encuentro intercomunitario para procurar estar juntos por unos días y competir; de un modo muy distinto a como se hace en el reahu, aunque con ciertas analogías, que hacen que el fútbol cobre interés.

La violencia social es la otra cara de la moneda, la muerte causada en duelo por alguna ofensa o en incursiones guerreras para raptar mujeres, responder a un supuesto maleficio chamánico o vengar alguna acción ofensiva, sigue estando presente en la actualidad. La intensa sociabilidad se conjuga con acciones de gran violencia. La competencia, por tanto, con expresiones sangrientas, ha sido y sigue siendo muy familiar entre los yanomamis, como pudimos apreciar personalmente en el shapono de Mamashatioteri, a cuatro horas de Mabetiteri. Ambiente por tanto que pudiera parecer propicio para la adquisición de una práctica venida de fuera que facilita la catarsis colectiva, la competencia entre dos bandos, aunque esta vez en clave no violenta. El fútbol, sin embargo, no solo es reproducido como un préstamo cultural adoptado, sino también adaptado a la idiosincrasia yanomami para hacerlo entendible, atractivo y culturalmente útil en un ejercicio de sincretismo. Circunstancia que encaja en la conocida tesis de Marshall Sahllins (1989) sobre la «indígenización de la modernidad», y que Christian Bromberger (1999) utiliza como «indigenización» para recordar cómo el fútbol se adapta y reinterpreta allí donde llega.

El fútbol, en el caso yanomami, no ha llegado a ser un sustituto de la guerra, como analógicamente venía a afirmar el etólogo Desmond Morris (1968) en el plano mundial, pero en su reciente introducción las implicaciones y consecuencias sociales que posee para este pueblo son muy notables. La competencia lúdicodeportiva entre equipos que lo caracteriza encaja en el esquema de alianzas y rivalidades yanomami, que provoca continuos procesos de fusión y fisión entre los shaponos. El papel comunicativo que desempeña en el ámbito comunitario e intercomunitario es manifiesto, al facilitar el encuentro y la rivalidad no sangrienta. Durante el trabajo de campo, su práctica diaria presenciada en Mabetiteri y los campeonatos ocasionales como el de Kukurital no entrañaron situaciones conflictivas que resaltar, aunque tuvimos conocimiento de palabra sobre los enfrentamientos violentos que, por motivos normalmente ajenos al desarrollo del juego, como son las venganzas personales, en ocasiones han surgido entre espectadores y también entre jugadores durante el desarrollo de trofeos que reúnen a varias comunidades.

$\mathrm{Al}$ indagar en la lógica interna de una y otra manifestación, cabe preguntar ¿cuál es el espíritu de la norma y la intencionalidad de la competencia en ambos eventos?

Entre los rarámuris, el objeto que se lanza (bola o ariweta) y la apuesta constituyen los ejes centrales que estructuran la carrera; no solo se corre por algo material que ganar, que alimente las expectativas y compense el esfuerzo invertido, sino también con algo que lanzar para hacerla más entretenida y distinguirse del resto de los animales, que corren sin más. «Los chabochis (extranjeros) corren como coyote», se les escucha decir, corren sin bola y sin ariweta. La carrera se construye en relación a esos dos elementos esenciales: no es 
válida sin que vaya acompañada del lanzamiento, y es impensable hacerla sin apuesta, la cual está igualmente presente en la realizada durante la infancia a modo de juego. La competencia cobra sentido en torno a ello y adquiere especial relevancia en razón a las distancias recorridas. Es en las grandes distancias en las que se puede poner en valor la cualidad emblemática que los caracteriza, la resistencia. Por consigna se asume que es preciso aguantar en todos los órdenes de la vida, «quien no aguanta, no vale, se pierde, muere», escuchamos. En esa convicción se mantienen y reproducen una carrera que constituye toda una metáfora de resistencia cultural (Acuña, 2005). Pero, además de poseer una gran resistencia y habilidad para lanzar, otra de las claves para obtener éxito en las carreras, y por extensión en la vida, es el trabajo en equipo, la colaboración y coordinación del equipo de corredores y del equipo de apoyo a éstos; la estrategia que marquen los corredores para relevarse en los lanzamientos y reservar la fuerza de los mejores para el final; la labor de quienes acompañan para cubrir los puestos de avituallamientos o alumbrar por la noche, además de animar, son cruciales, al extremo que no siempre ganan los más resistentes sino quienes cuentan con un mejor apoyo. Todos estos elementos normativos ayudan a entender los valores implícitos que se desprenden de una carrera en la que compiten dos grupos por llegar el primero, en la que solo uno ganará la carrera y, por inclusión, la apuesta. Sin embargo, aunque solo sea un grupo el que resulte ganador, no debe pasar desapercibido cómo se asumen los resultados. Terminada una carrera grande de más de 20 horas ininterrumpidas, resulta realmente difícil averiguar qué corredor o corredora ha ganado fijándose en la expresión de su rostro o en su comportamiento; por lo general no se dramatiza el resultado, quien gana no se presenta exultante de alegría y menos aún arrogante o soberbio con el triunfo; y quien pierde no se muestra abatido o deprimido, triste y desanimado; en ambos casos se muestran rostros serenos, como si nada hubiera pasado, cada cual ha cumplido su papel, había dos posibilidades: ganar o perder, y a cada cual le ha tocado una en esta ocasión, habrá más ocasiones en la que el resultado podrá cambiar. En los apostantes se aprecia mejor los resultados obtenidos, unos se manifiestan más contentos que otros, aunque tampoco de manera exagerada. Actitudes serenas en definitiva, de satisfacción generalizada, que conecta con la cosmovisión de un pueblo que organiza carreras con destinatarios humanos y divinos. Se gane o pierda la carrera y la apuesta, todos han contribuido en ella para tener contento a Onorúame. En la interpretación de los resultados, la mayor o menor excelencia de los corredores y la mejor o peor atención recibida por sus respectivos equipos de apoyo serán motivo de conversación, pero también la supuesta intervención de algún agente maléfico en perjuicio de alguno, agente que no invalida el resultado porque aunque no sea visible y constituya una permanente amenaza, es asumido como parte de la existencia y, como no, de la competencia en la carrera. De lo que no se habla es de la buena o la mala suerte de unos y otros, en un contexto en el que el posible desfallecimiento de un corredor, o la pérdida o rotura de la bola en la noche, no ocurre por azar, todo tiene su causa y su explicación, aunque ésta se sitúe en otro plano de la realidad. En las más de 30 carreras observadas, al menos un tercio de ellas grandes, salvo algún que otro incidente motivado por la embriaguez de algunos espectadores, o retrasos injustificados para comenzar, se desarrollaron de acuerdo al esquema descrito, sin mayores problemas; aunque por oídas, como ya se señaló, la controversia y el conflicto surge en ocasiones por los motivos ya indicados.

Entre los yanomamis, por su parte, la práctica del fútbol resulta atractiva y cobra sentido porque se hace conectar con elementos de la propia tradición, y en concreto con la lucha ritual. En el ámbito comunitario de los lugares menos expuestos al ambiente exterior, como Mabetiteri, la lógica aplicada es que todos ganan el partido en la medida que metan goles, al igual que todos ganan con la práctica ritual de la lucha. En la lucha lo importante es asumir el desafío del rival, dar y recibir golpes de manera pautada y demostrar ambos ser waiteri (Albert, 1989); en el fútbol lo importante es pasar un rato divertido, marcar y encajar goles (al igual que se dan y reciben golpes en el otro escenario) y terminar con la satisfacción de los que se hayan podido obtener, sin que tampoco haya perdedores. De manera espontánea y no menos sorprendente, este pueblo aguerrido sustrae así la esencia lúdica y humanística, la que nos hace ganar a todos, de una práctica global rodeada de intereses e instalada cada vez con más intensidad en la idea de ganar a toda costa y como sea; lo cual hace pensar a qué pueblo habría que asignar el atributo de «feroz» (Chagnon, 1968), al menos en este terreno.

En cuanto a los campeonatos realizados en el ámbito intercomunitario, como ocurrió en Kukurital, las asociaciones y transferencias del tradicional reahu son de interés para entender la lógica de la acción (Acuña, 2014). En ambos casos la comunidad anfitriona que organiza el evento pone fecha e invita a otras comunidades para que acudan al encuentro. En ambos casos hay 
competencia protagonizada por varones que genera expectación: verbal y física en el reahu, deportiva en el fútbol. Competencia que se desarrolla por parejas, de personas en el primer caso y de equipos en el segundo, que representan a comunidades. La aplicación normativa es pactada y consensuada entre los rivales: en los enfrentamientos de lucha se respetan los tres golpes alternativos y en el fútbol las reglas del juego establecidas. En ninguno de ellos cabe la rendición, una vez que se empieza hay que acabar, bien sean la serie de golpes o el tiempo de juego reglamentario. En ambos se busca reafirmarse en algún sentido: como waitheri en la lucha y como buen equipo en el fútbol. Analogías que en definitiva favorecen su aceptación. El sistema de puntuación descrito en el campeonato de Kukurital para determinar el ganador final, constituye un buen indicador del espíritu de la norma, al privilegiar el fútbol de ataque con el marcaje de goles (sumados todos al final), por encima incluso de ganar o perder puntualmente. De nuevo, el carácter guerrero y combativo como pueblo se refleja en una permanente disposición de ir siempre adelante, a la ofensiva en su manera de entender el fútbol; así como el hecho de mantenerse siempre alerta y preparado para el combate, que con frecuencia es sorpresivo, lo podemos asociar con la circunstancia de no considerar desventajoso jugar varios partidos seguidos en los emparejamientos con rivales que se encuentran frescos, la sobrecarga de esfuerzo no es excusa dentro de un contexto en el que mantener la vida exige estar siempre preparados para afrontar las dificultades y amenazas en cualquier momento, muchas veces inesperados.

Los contextos ambientales, históricos y socioculturales son muy distintos entre rarámuris y yanomamis, al igual que lo es la carrera y el fútbol que respectivamente practican, sin embargo, siendo ambos pueblos amerindios (descendientes de los pueblos originarios de América) y tratándose de deportes de competición, ¿existen patrones comunes en sus realizaciones?

Si reflexionamos sobre la puesta en escena de ambas actividades, es posible destacar al menos dos significativos rasgos comunes. Uno de ellos no tiene nada de particular porque se puede apreciar en otros muchos lugares y resulta característico del deporte de competición: la fruición por el ejercicio, unida al desempeño intenso y serio de la acción (Cagigal, 1981a). Rarámuris y yanomamis se meten a fondo en el papel cuando compiten y, aunque no pierdan el componente lúdico, procurarán ejercitarse al máximo de sus posibilidades. Ya sean pequeñas o grandes las carreras, quienes las ejecuten pondrán todo su empeño por hacer pasar la bola o la ariweta en primer lugar por línea de meta, llegarán a colocarse al límite de sus fuerzas por ganar y hacer ganar a su bando y partidarios. Al igual que en los partidos de fútbol, haya o no trofeo en juego, sin dejar que sean divertidos, los yanomamis se emplean con entusiasmo e intensidad; corren con velocidad, se disputan con fuerza la pelota, se afanan todo lo que pueden y no cejan en el empeño por conseguir el ansiado gol. Tanto unos como otros disfrutan de la actividad, les resulta divertida, pero lejos de tomárselas a broma, puestos en acción y dispuestos a competir, se convierten en adversarios que focalizan toda su atención y energías en el papel a cumplir con un alto grado de autoexigencia.

El otro rasgo común y distintivo de ambos casos, sin embargo, sí resulta peculiar. Si por lo general, el deporte moderno de competición, en sus distintos niveles y modalidades, tiene importantes implicaciones y consecuencias, ya sea de carácter social, económicas o anímicas por el hecho de ganar o perder, cobrando con frecuencia un papel trascendental, en los casos aquí tratados la actitud es similar en cuanto a no trascendentalizar tal circunstancia. La competencia en la carrera tradicional rarámuri es muy elevada, al igual que la inversión de esfuerzo y las expectativas de los seguidores con apuestas incluidas, pero se entiende que no es más que una carrera entre muchas. En el fútbol yanomami, con todo el entusiasmo e intensidad que siempre ponen los jugadores, ya vimos que en el ámbito comunitario ni siquiera se habla de perdedores, y en los campeonatos entre comunidades el respeto a las normas del juego y a las decisiones arbitrales es máximo, aceptándose igualmente sin mayor controversia el que resulte finalmente ganador, de acuerdo a las reglas establecidas. Aunque se aspire siempre a ganar, como objetivo de la competición, que se consiga o no es asumido con normalidad, ya que son las dos posibilidades del juego. Sencillo razonamiento empleado por rarámuris y yanomamis que se resume en competir y aceptar los resultados con deportividad, una actitud que no debería sorprender si no fuera porque la tan mencionada deportividad, con mucha frecuencia está ausente de la sociedad moderna que más habla de ella.

\section{Conclusiones}

Tras todo lo expuesto, de las explicaciones aportadas en relación con los objetivos se desprende lo siguiente: Las peculiaridades encontradas en actividades deporti- 
vas arraigadas en la costumbre, como la tradicional carrera rarámuri, y deportes importados, como el fútbol yanomami, cobran sentido en base a los respectivos contextos de realización. Las implicaciones y consecuencias de la competencia en ambos casos sobrepasa la esfera estrictamente deportiva, para conectar con diferentes planos de la realidad: los yanomamis encuentran en el fútbol un atractivo recurso de encuentro social y rivalización de manera no violenta; y los rarámuris, además de ello, tienen en la carrera un medio de transacciones económicas y un motivo más para reforzar sus creencias religiosas. Las normas establecidas para regular la competencia en cada caso se hallan vinculadas con la idiosincrasia cultural, incluso cuando se trata de una actividad importada. En ambos casos observamos pautas comunes en cuanto a la manera desdramatizada de asumir el hecho de ganar o no ganar. Y ambas modalidades de competición incorporan al respectivo acervo cultural valores con los que la práctica se reproduce en el tiempo como un incentivo cargado de sentido que dinamiza la vida social.

A falta de matices por razones de espacio, la visión de la competencia en las actividades deportivas descritas constituyen el retrato de una época, sin embargo, los tiempos cambian y con ellos las circunstancias y los valores. Junto a los escenarios referidos, es apreciable ya, tanto en la sierra Tarahumara, como en el Alto Orinoco, la llegada de poderosas influencias por diversas vías (sociedad mestiza, escuela, medios de comunicación, etc.) que alteran las maneras de afrontar las competencias mencionadas. Los rarámuris son invitados a participar en ultramaratones convencionales, como las 100 millas de Los Ángeles o Colorado; en la misma Tarahumara se celebra la ultramaratón de los Cañones (de $90 \mathrm{~km}$ ), en la que los rarámuris compiten con centenares de corredores y corredoras mexicanos y de otros países, esta vez sin bola o ariweta y sin apuestas. Por otro lado, a los mestizos se les acusa de haber pervertido el sistema de apuestas en las carreras tradicionales, al comprar la voluntad de algunos corredores para que se dejen perder. Los yanomamis, por su parte, tienen acceso en La Esmeralda a la televisión vía satélite en la que pueden observar la pasión con la que se vive el fútbol en el resto del mundo, los muchos intereses que lo rodean, los gestos y palabras que hablan de él, y las maneras con que se viven las victorias y las derrotas. Asimismo, son invitados a participar en los Campeonatos o Juegos Panindígenas, en los que tienen ocasión de competir en diferentes actividades deportivas, y en especial en fútbol, con otros grupos étnicos, siguiendo las normas de Comités de Competición que lo entienden de un modo más cosmopolita. El fútbol se presenta como un incentivo para aumentar los encuentros intercomunitarios e interétnicos, que puede inducir significativas transformaciones sociales y culturales. El tiempo dirá, por tanto, cómo evolucionarán en el futuro y qué quedará de las maneras y actitudes con que vimos competir a rarámuris y yanomamis a principios del siglo XXI; los excesos, el fanatismo y el ruido que envuelve las competiciones deportivas, muy probablemente modifiquen en breve el panorama aquí presentado, en un mundo cada vez más interconectado en el que resulta muy difícil quedar al margen de ese tipo de influencias, pero sea como sea, es importante tener presente, aunque sea en la memoria, cómo estas comunidades amerindias, lejos de los medios de comunicación que las visibilice, interpretan a su modo la competencia deportiva, por lo que pueda servir a quienes forman parte de la sociedad autodenominada «del conocimiento».

\section{Referencias}

Acuña, A. (2005). Funciones y definición conceptual de la carrera rarámuri en la Sierra Tarahumara. Nueva Antropología. Revista de Ciencias Sociales, 64, 149-172.

Acuña, A. (2006). La construcción cultural del cuerpo en la sociedad rarámuri de la sierra Tarahumara (México). Quito: Abya Yala.

Acuña, A. (2010). Estructura y función del fútbol entre los Yanomami del Alto Orinoco. Revista Española de Antropología Americana, 40(1), 111-138.

Acuña, A. (2014). Del chamanismo (hékuramou) y la festividad social (reahu) al fútbol yanomami: una nueva manera de compartir y competir. Nueva Antropología. Revista de Ciencias Sociales, 80, 111-138.

Albert, B. (1989).Yanomami «violence»: Inclusive fitness or ethnographer's representation. Current Anthropology, 30(5), 637-640. doi.org/10.1086 / 203793

Alès, C. (1984).Violence et ordre social dans une société amazonienne. Les Yanomami du Venezuela. Études rurales, 95-96(1), 89-111.

Barandiarán, D. (1965). Mundo espiritual y shamanismo Sanemá.Antropológica, 15(1), 1-28. doi.org/10.4100/ jhse.2010.53.03

Basauri, C. (1926). The Resistence of the Tarahumaras. Mexican Folkways, 2(4), 40-47.

Bennett, W., \& Zingg, R. (1978 [1935]). Los Tarahumaras, una tribu india del norte de México. México: Instituto 
Nacional Indigenista.

Blanchard, K., \& Chesca, A. (1986). Antropología del deporte. Barcelona: Bellaterra.

Bourdieu, P. (1988). Cosas dichas. Barcelona: Gedisa.

Bredemeier, B.J. (1994). Children's moral reasoning and their assertive, aggressive, and submissive tendencies in sport and daily life. Journal of Sport and Exercise Psychology, 16(1), 1-14. doi.org/10.1123/ jsep.16.1.1

Bromberger, C. (1999). El revelador de todas las pasiones. En S. Segurola (Ed.): Fútbol y pasiones políticas (pp. 27-36). Madrid:Temas de Debate.

Cagigal, J.M. (1981a). ¡Oh Deporte! (Anatomía de un gigante). Valladolid: Miñón.

Cagigal, J.M. (1981b). Deporte: espectáculo y acción. Madrid: Salvat.

Caillois, R. (1958). Les Jeux et les Homes. Paris: Gallimard. Carlin, J. (2009). El factor humano. Barcelona: Seix Barral.

Cazorla, L.M. (1979). Deporte y Estado. Barcelona: Labor.

Chagnon, N. (1968). The fierce People. New York: Holt, Rinehart \& Wiston.

Chiappino, J. (2003). La cura chamánica yanomami y su eficacia. En C. Alès \& J. Chiappino (Eds.): Caminos cruzados. Ensayos en Antropología Social, Etnoecología y Etnoeducación (pp. 39-68). Mérida:IRD Éditions/Universidad de Los Andes, GRIAL.

Diem, C. (1966). Historias de los deportes. Barcelona: Diamante.

Durán, J. (2013). Ética de la competición deportiva: valores y contravalores del deporte competitivo. $\mathrm{Ma}$ teriales para la historia del deporte, 11, 89-115.

Durán, L.J., y Jiménez Martín, P.J. (2006). Valores en movimiento. La actividad física y el deporte como medios de educación en valores. Madrid: Consejo Superior de Deportes.

Fernández-Río, J.; Cecchini, J.A., \& Méndez-Giménez, A. (2014). Efectos del aprendizaje cooperativo sobre la competencia percibida, la motivación, las relaciones sociales, el esfuerzo y el aburrimiento de futuros docentes de educación primaria. Infancia y aprendizaje, 37(1), 57-89. doi.org/10.1080/ 02103702.2014 .881650

García Ferrando, M. (1990). Aspectos sociales del deporte. Una reflexión sociológica. Madrid: Alianza Editorial.

Geertz, C. (1983) La interpretación de las culturas. Barcelona: Gedisa.

Goffman, E. (1987). La presentación de la persona en la vida cotidiana. Buenos Aires: Amorrortu.

Gutiérrez, M. (1995). Valores sociales del deporte. La Activi- dad Física y el Deporte como transmisores de valores sociales y personales. Madrid: Gimnos.

Heineman, K. (1991). Tendencias de la investigación social aplicada al deporte. EnVV.AA. (Eds.). Políticas deportivas e investigación social (pp. 5-41). Pamplona: Gobierno de Navarra.

INE (2011). XIV Censo de Población y Vivienda 2011. Resultados Población Indígena. República Bolivariana de Venezuela. Recuperado de http://www.ine.gov.ve/ d o c u me n t os / D e mografia / CensodePoblacionyVivienda/pdf / ResultadosBasicos.pdf

INEGI (1995). Chihuahua. Conteo de población y Vivienda, 1995. Resultados definitivos. Tabulados básicos. Aguascalientes: INEGI.

INEGI (2015). México - Encuesta intercensal 2015. Recuperado de https://www.inegi.org.mx/rnm/ index.php/catalog/214/related_materials?idPro=

Kennedy, J.G. (1970). Inapuchi. Una comunidad tarahumara gentil. México: Instituto Nacional Indigenista.

Lizot, J. (1976 ). Le Cercle des feux. Faits et dits des Indiens Yanomami. París: Editions Seuil.

Lumholtz, K. (1994 [1902]). El México desconocido. México: Instituto Nacional Indigenista.

Lueschen, G. (1970). Cooperation, association and contest. Journal of Conflict Resolution, 14, 21-34.

Lüschen, G. \& Weis, K. (1976). Sociología del deporte. Valladolid: Miñón.

Mattei Muller, M.C.( 2007). Lengua y cultura Yanomami. Diccionario Ilustrado Yanomami - Español / Español-Yanomami. Caracas: Edición propia.

Merrill, W. (1992). Almas rarámuris. México: CNCA/ INI.

Monjas, R.; Ponce, A., \& Gea, J.M. (2015). La transmisión de valores a través del deporte. Deporte escolar y deporte federado: relaciones, puentes y posibles trasferencias. Retos: nuevas tendencias en educación fisica, deporte y recreación, 28(1), 276-284.

Morris, D. (1968). El mono desnudo. Un estudio del animal humano. Madrid: Plaza y Janes.

Ossorio, D., \& Fernández Sánchez, M.T. (2011). El influjo de las ideologías dominantes y el proceso de globalización en el deporte. Una propuesta del modelo de desarrollo para la integración de valores en las actividades físico-deportivas en el deporte escolar.Lecturas: Educación Física y Deportes, Revista Digital, 162(11), 1-16. Recuperado de http:// www.efdeportes.com/efd162/ideologias-dominantes-y-globalizacion-en-el-deporte.htm

Parlebas, P. (2001). Juegos, deporte y sociedad. Léxico de 
praxiología motriz. Barcelona: Paidotribo.

Pérez Flores, A.M. (2015). Deportes contemporáneos: tipos de deportistas y modelos deportivos en España. Anduli. Revista Andaluza de Ciencias Sociales, 14, 79 98.

Pérez Turpin, J.A. (2002). La competición en el ámbito escolar: un programa de intervención social. Tesis Doctoral. Departamento de Didáctica General y Didáctica Específica. Universidad de Alicante.

Piernavieja, M. (1966). Depuerto, deporte, protohistoria de una palabra. Citius, Altius, Fortius, 1-2, 5-190.

Sahllins, M. (1989). Cosmologies of Capitalism: The Trans-Pacific Sector of «The World-System». Proceedings of the British Academy, 74, 2060-2112.

Sánchez Pato,A.; Mosquera, M.J.; Bada, J.D. , \& Cebrián, Y. (2008). Educación en valores a través del deporte. Guía práctica. Sevilla: Wanceulen.

Santiago, J.J. (2002). El desarrollo de valores sociales positivos dentro del deporte escolar. EFDeportes.com. Revista Digital, 47(4), 1-2. Recuperado de https: / / www.efdeportes.com/efd47/valores.ht.

Sipes, R.G. (1973). War, sport and aggression: a preliminary causal model of cultural patternig. $I X$ International Congress of Anthropological Sciences. Chicago.

Stone, G.P. (1971).Wrestling-the great American passion play. En E. Dunnig (Ed.). The Sociology of Sport (pp. 301-335). Londres: Frank Cass.

Veroz, R., Yagüe, J. Ma ., \& Tabernero, B. (2015). Incidencia de dos modelos decompetición de fútbol sobre los valores socio-educativos en prebenjamines. Retos. Nuevas tendencias en Educación Física, Deporte y Recreación, 28, 84-89.

\section{(Footnotes)}

${ }^{1}$ Tras la finalización de las respectivas investigaciones fueron publicados sus resultados en diversos traba- jos por separado (Acuña, 2005; Acuña, 2010). No obstante, al echar la vista atrás sentimos que faltaba por elaborar un artículo como el presente, en el que reflexionar conjuntamente sobre las dos manifestaciones deportivas mencionadas para observar las lógicas que aplican a la competencia en sus respectivos contextos, en contraste con los más conocidos o habituales de las sociedades modernas globalizadas.

${ }^{2}$ La carrera de bola al modo que la siguen realizando los rarámuris en la actualidad, y en menor medida sus vecinos tepehuanes, era practicada en el pasado por numerosos pueblos indígenas que ocupaban un extenso territorio situado en lo que hoy es la región noroccidental de México y la suroccidental de Estados Unidos.

${ }^{3}$ Desde la perspectiva rarámuri, la fuerza y resistencia de los corredores no solo depende del estado físico, también del estado de sus almas.

${ }^{4}$ Será éste un capítulo de análisis de resultados pero no tanto de discusión, en la medida que por la singularidad de los casos tratados no dispongo de investigaciones de similares características y en semejantes contextos con las que poder comparar o contrastar los datos aquí producidos. Por otro lado, excluí la posibilidad de comparar la carrera rarámuri con las ultramaratones modernas y el fútbol yanomami con la convencional forma de jugar al fútbol en el resto del mundo, porque forzar la comparación de realidades situadas en contextos tan distintos podría distorsionar más que aclarar comportamientos, dificultando la comprensión al lector. Por razones de espacio he sintetizado al máximo las explicaciones ofrecidas en este capítulo para dar respuesta a las preguntas de investigación, no obstante, quien desee ampliar la información, en publicaciones anteriores (Acuña, 2005, 2006, 2010, 2014) son tratados ambos casos por separado y se ofrecen suficientes detalles de observación y testimonios orales de informantes que dan consistencia a la argumentación.
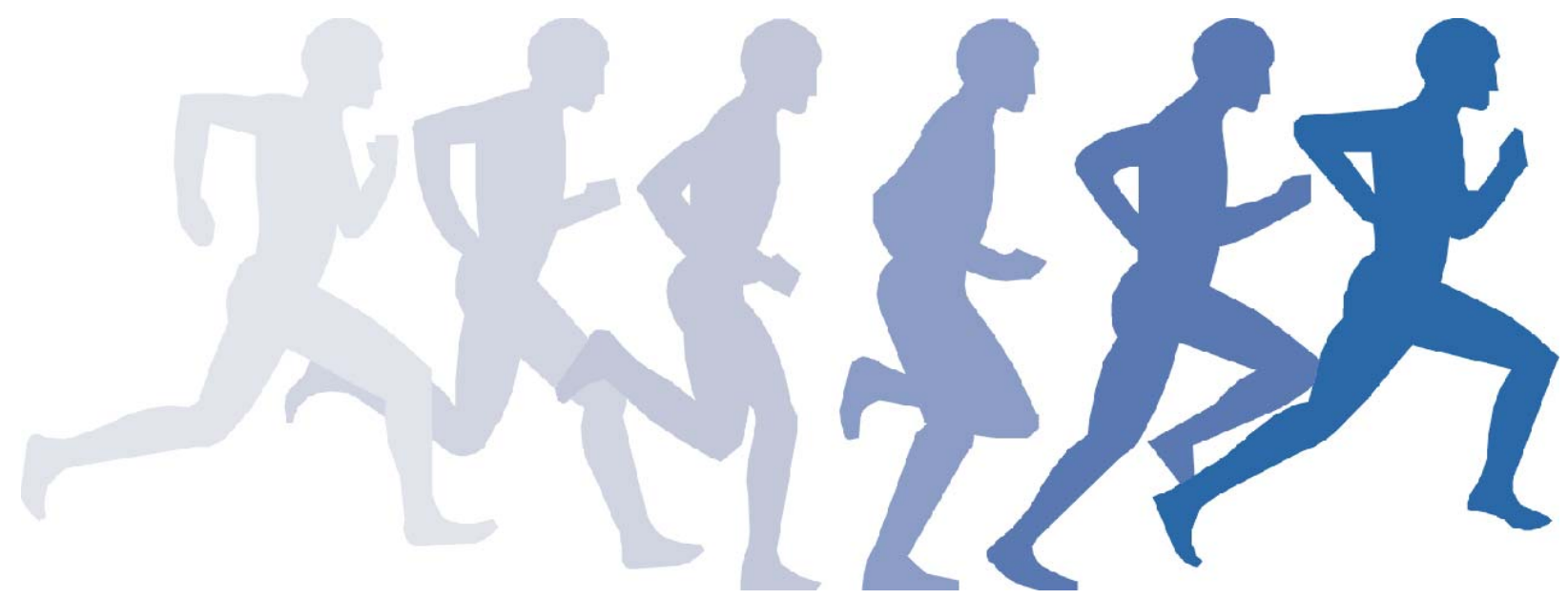